\title{
Recreating Government through Effective Knowledge Management
}

\author{
Greg Robins and Janice Burn \\ Edith Cowan University, Australia
}

\begin{abstract}
This paper discusses the use of Intranet technology as a means for the delivery of more effective government services. Specifically, we look at how a Western Australian Government Agency, the Ministry for Sport and Recreation, with geographically dispersed sites has utilised Intranet technology to deliver corporate knowledge to all staff. This has laid the foundation for egovernment delivery across the region.
\end{abstract}

\section{INTRODUCTION}

Western Australia is an extremely large and isolated state covering 2.5million sq kilometres and spanning $2400 \mathrm{~km}$ from north to south. Many country towns are highly remote from centralised public services with limited access to current communications technology. Given these circumstances it is essential that information systems are developed to enable effective access to both information and electronic communications. Internet/Intranet technology lends itself perfectly to the establishment of electronic communications between these locations with relatively inexpensive communication links. They are hence powerful enablers of knowledge sharing across functions, departments and geographical locations rendering knowledge management as a core organisational competence (Kanter, 1999; Newell et al, 1999).

The paper begins with an overview of the definitions of knowledge management. The authors review current thinking on what makes sound knowledge management practice and examine how Intranet technology assists in developing a knowledge focused organization. The definition of knowledge management is applied to a case study which considers Intranet developments within a government agency that has a centrally located office with a number of geographically dispersed sub offices. The 
case enables the review of the features of Intranet technology, in particular the premise that Intranets are a 'de-centred' technology consisting of loosely coupled systems (Newell, Scarborough, Hislop and Swan 1999) within the context of its implementation and use as a knowledge management tool.

\section{KNOWLEDGE MANAGEMENT}

Vail (1999) defines knowledge as information made actionable in a way that adds value to the enterprise. There are two basic types of knowledge:

- Implicit knowledge - knowledge that is locked in people's minds that comes from their experiences and skills.

- Explicit Knowledge - knowledge that has been articulated and captured in formal models, rules and procedures..

It can be said that explicit knowledge forms the basis of implicit knowledge. For someone to develop implicit knowledge they must first gather explicit knowledge and utilize this together with their skills and experiences to develop implicit knowledge. Knowledge is produced as the result of human interpretation and analysis rather than data processing (Moody and Shanks 1999). The essential distinction is explicit knowledge can be digitized or turned into information while implicit knowledge is intrinsic to people. Information only creates value for clients when it is applied (Dawson 2000). The merging of the two is integral to creating value from explicit knowledge and leveraging information repositories to create competitive advantage or providing value for clients.

There are many definitions of Knowledge Management and strong debate on defining and capturing implicit knowledge. Many would argue that once implicit knowledge has been captured it becomes explicit knowledge or information. Knowledge management is about turning raw data into information and from there into knowledge (Kanter 1999). It is about understanding how to transfer knowledge to users, how to add value to the information, how to transfer data into information and how that information can be transferred into knowledge.

Knowledge management is a discipline that promotes an integrated approach to identifying, managing and sharing all of an enterprise's information assets. These may include databases, documents, policies and procedures as well as previously unarticulated expertise and experience resident in individual workers. Knowledge management issues include developing, implementing and maintaining the appropriate technical and organizational infrastructures to enable knowledge sharing (Butler 2000). The major objective of knowledge management is to make effective use of information and to combine this with effective use of 'know-how' and expertise in an organisation.

Sveiby defines a knowledge organisation as one which:

- Provides services rather than products; 
- Sells its knowledge and expertise to solve complex problems for its customers;

- Consists of employees who are highly qualified and educated professionals (knowledge workers), and

- Intangible assets are much more important than tangible assets. (Sveiby 1997) This definition closely relates to the organization that forms the basis of the case study of this paper. The organisation is the Ministry of Sport and Recreation, a Western Australian state Government Department. It is very much a service organisation responsible for providing sporting bodies in WA with a sport consultancy. Its employees are sport specialists highly qualified in a wide variety of disciplines within the sport industry.

\section{CASE STUDY - THE MINISTRY OF SPORT AND RECREATION}

\subsection{Research Method}

The research methodology was based on action research. One of the authors was fully involved in the implementation of the Ministry's wide area network and the development of the Intranet system. This included involvement in the three committees that were established specifically to steer the Ministry's information requirements.

These committees are:

- The Information Technology Steering Committee,

- Internet Committee, and

- Intranet Committee.

These three committees each have representatives from each section within the organisation and as such provided an extensive insight into the information requirements for the organisation.

\subsection{Background to Ministry of Sport \& Recreation}

The Ministry of Sport and Recreation is an organisation that has a number of offices strategically located in country areas of Western Australia and a central office located in Perth. Its main functions are to:

- Act as a consultancy to assist sporting organisations develop their sport and operational functions,

- Assist local Government authorities develop and sporting infrastructure,

- Provide research information on current initiatives in the sporting and recreation industry particularly in relation to preventative health and social issues such as child protection or drugs in sport, and 
- Increase participation rates in sporting and recreational pursuits.

As indicated by the Director, Business Management

'Until late 1999 the Ministry of Sport and Recreation operated in an information technology environment that was largely ineffective and, in the context of the

'Statewide' nature of the Ministry, to some extent dysfunctional.'

In particular:

- The information technology environment was focused on single user functionality and completely devoid of corporate tools;

- Corporate databases were being developed using software that precluded easy and meaningful access by Statewide offices (database update was still being done by 'floppy disk' transfer);

- There was no customisation of office tools to assist with document creation and ensure maintenance of corporate standards;

- There were no tools to assist with document management including document storage and document tracking and document location (requiring staff to spend many hours per week simply searching the network locating documents stored in one of many thousand directories);

- There was no mechanism for readily accessing corporate management information such as operational plans, financial reports, documentation on achievements and issues, corporate policies and procedures. human resource management information. resource bookings, internal telephone lists and functional responsibilities, client information. ministerial correspondence, strategic dates (corporate calendar).

There was not one single web based application nor any plans to progress down this path.

In terms of communications, the Ministry interacted with its regional offices in much the same way as it did in the early 1990's. The mechanism for communications was inconsistent with contemporary business requirements; sound management practice; and every other comparable State Government Agency (e.g. Aboriginal Affairs, Legal Aid etc. who have implemented state of the art communications frameworks). The idea was to develop a communication infrastructure that enabled the linking of all offices, develop systems that captured organizational knowledge and deliver this directly to each desktop. This was seen as the Ministry's Knowledge Management vision.

\subsection{Corporate Context}

The Ministry's purpose is to 'Enhance the lifestyle of Western Australians through their participation and achievement in sport and recreation.' In order to assist in achieving this, one of the Ministry's visions is to have skilled and informed people delivering services. Hence, a new management framework was required that:

- Guaranteed all staff focused on approved outputs and outcomes; 
- Guaranteed corporate communications on achievements and work plans;

- Ensured that all staff have the opportunity to be informed;

- Ensured that resource issues and program management issues are discussed and that major issues 'bubble up' for executive consideration.

The principle driving force behind the information reforms was the need to deliver an environment in which all Ministry staff could substantially improve productivity and inherently devote more time and resources to program delivery (meeting client needs). The Ministry established a Statewide data communications infrastructure and established office productivity tools to ensure all staff have access to essential information. It has developed an Intranet site, known as The Arena. The Arena provides all staff, regardless of location, access to a wealth of information including, but not limited to, a client management system, Ministry operational plans, monthly achievement reports, policies and procedures and financial reports.

\subsection{Organisational Culture}

The Ministry of Sport \& Recreation had a history of decentralized development. All regional offices were isolated from the central office and as such had developed their own policies and procedures. Many had developed their own web presence, lacked internal information systems and had no access to corporate information. Within the central office the various divisions worked independently of each other, there were no corporate information systems nor effective management of electronic or paper based documents. Staff were provided with computers for email and developing documents but stored these in personal areas making the information inaccessible to the organisation. The IT section consisted of two staff members with responsibility for providing technical advice and setting up computers on desks. There was limited strategic information planning revolving around a hardware replacement strategy. 


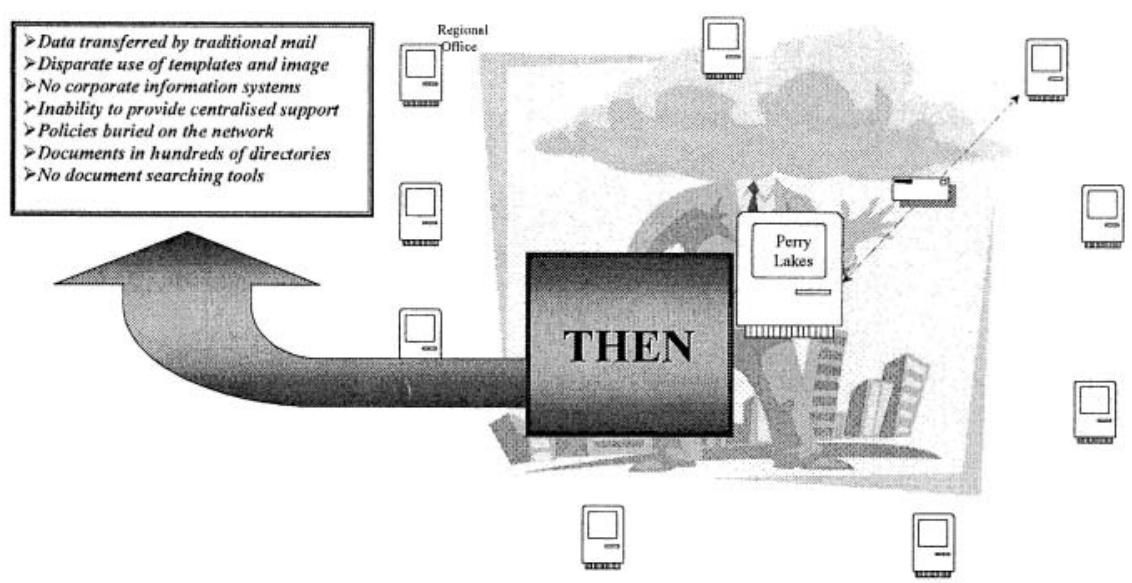

Figure 1. Ministry Information Infrastructure Pre Arena

In 1999 a new Chief Executive Officer was appointed and there was a complete change of the corporate executive team. This lead to a refocus on Information Management and an Information Branch was initiated with the responsibility to develop a statewide network and information infrastructure to support the development of corporate information systems and the implementation of Knowledge Management principles.

\subsection{The Project}

This project reflects a massive change to the way the Ministry carries out its business. Implementation of The Arena and associated office productivity tools and management practices represents the single biggest change the Ministry had experienced in many years. The staff have been required to adopt a completely different technology to the one they were used to as well as be prepared to change the way that they carried out their daily tasks.

To ensure that the change process was managed effectively the Ministry consciously went about:

- Ensuring that all staff are clear on who has carriage/responsibility for the particular change process required,

- Ensuring user involvement and user commitment,

- Ensuring that those officers who were charged with leading the change process actually had the necessary skills required,

- Ensuring training needs that arise as a consequence of the change process were identified and addressed and supported with documentation,

- Setting and promoting timelines and monitoring progress (effective planning)

- Identification of problems and solutions, and 
- Ensuring ongoing communication - upwards, downwards and across divisions/programs.

\subsubsection{Responsibility}

For each component of the implementation responsibility for managing the change was determined (the change agent). While overall responsibility was vested in the Director, Business Management, responsibility for individual components included the Director, the Manager, Information Services, the Manager, Human Resources, the Manager, Finance and Administration and the Principal Projects Manager, Policy and Research Division. It was the responsibility of individual officers to identify an implementation timetable; develop specification; consult staff; manage resources; manage implementation; liase with Manager, Information Systems (including coordination of launches on the Arena); ensure availability of documentation; and promote system take up.

Use Involvement and Commitment. A strategic approach to user involvement was adopted. At the outset a series of 'show and tell' sessions were conducted identifying what was possible in the way of office productivity and information access; an all staff conference was held in March 2000 to demonstrate and further discuss the proposed strategy for the Ministry; feedback was sought from staff on proposed directions; a Strategic Information Systems Steering Committee was formed. This committee was representative of the whole Ministry and had the task to oversee all projects, bringing to the table comment from the areas they represented and make decisions that reflected the corporate vision. During each phase of the project staff were asked for comment and feedback through the information sessions. Following on from the project a monthly staff forum session was established to provide an avenue for informing staff of new developments as well as enabling staff to request training in a particular area or identify opportunity based information developments.

Skills Required. At the start of the project it was recognised that staff within the information systems area needed to be up-skilled and re-skilled on contemporary networking solutions. Management of the project, in the first instance needed sound strategic planning and interpersonal and communications skills in preference to a high level of technical IT based skills; and transitional difficulties could be minimised with a methodical and systematic approach to implementation and by revisiting every tool to ensure that 'it was easy', it met user needs, had been thoroughly tested and was supported by plan that included:

- user documentation;

- coordination between training program and set up of user desktop;

- common user interface.

In particular, arrangements were made to engage a proven highly skilled network administrator to provide hands on coaching and knowledge transfer for one day per 
week (this was done through negotiation with another public sector agency); engage on a short term basis an additional network administrator to 'hold the fort' during implementation; where relevant, include in every contract the requirement to provide skills transfer to Ministry staff (eg development of professional templates); appoint an IS Manager who met the criteria outlined above but who also had a practical understanding of where the Ministry needed to go and how to get there with regard to information Management (and ideally had some experience in using the required tools).

Training. Education was seen as the key to allay the fears of staff. Sessions on 'communicating the why' were conducted at every opportunity. Prior to the commencement of the project a session was conducted at a whole of staff conference and similar sessions were given to staff at each monthly staff meeting. The message: The project would improve quality in projects and allow MSR to ramp up to new technologies. There was a constant reinforcement with people as to why they were changing and what was in it for them. Of paramount importance was the training of all staff whilst minimising disruption to their daily routine. An initial group of change leaders representative of each division were identified to trial the training programme and to transfer to the new system prior to the full rollout. During the trial session members of the group were encouraged to provide critical comment to enable the system and training programme to be honed to suit the Ministry.

To minimise disruption four staff at a time were provided with a three hour session. Whilst the training was taking place a new computer was set up on their desk to enable them to be immediately productive upon their return and to ensure that they could put into practice what they had learned. At the end of each week a follow up session was provided that reinforced the initial training as well as providing a mechanism for staff to provide further input and feedback.

In summary, no new tools were put on the desks of staff without them first attending a formal training program and having access to documentation.

Timelines (Planning). From the outset it was agreed with Corporate Executive that the central office would be fully operational by June 302000 (this was achieved a week earlier) with access to most of the proposed productivity tools completed at the same time. To achieve the above it was necessary to ensure that each component of the project had a timeline and that there would be a number of things that could be undertaken concurrently. The timely completion evidenced that mechanisms put in place to deliver the project were successful.

Problem Identification and Solution. What was important was that there was a framework and a mechanism for having them quickly resolved. In addition to the user consultation and the IT Strategic Directions Committee, the Information Systems Branch met weekly with the Director, Business Management to report/monitor/review progress and to identify action that needed to be taken to accelerate the project. These meetings provided a guaranteed forum for: 
- Prioritising;

- Ensuring nothing slipped between the cracks;

- Identifying who else needed to be involved/informed (including when and why);

- Ensuring a common understanding of status and issues;

- Identifying what training was emerging/required;

- Focussing on timelines.

\subsubsection{Communication}

Issues in this area are largely addressed above. Suffice to say a communications strategy was in place and a number of mechanisms for ensuring effective communication were used. The basic premise underlying the project was to manage the introduction and ongoing use of information technologies to support the more flexible, complex, and integrated structures and processes demanded by the Ministry and its staff. It is recognised that the introduction and ongoing use of information technologies is an ongoing process made up of opportunities and challenges which are not necessarily predictable at the start. At the end of the day, the project identified three types of change that needed to be dealt with and that will continue over time:

1. anticipated,

2. emergent, and

3. opportunity-based.

These can be related to Zack's strategic framework for knowledge management. (Zack, 1999). As a first step the organisation needs to determine the value of knowledge to its business. In other words it must align its knowledge resources and capabilities to the intellectual resources of its strategy. This should be measured against two dimensions and related to knowledge aggressiveness. The first dimension addresses the extent to which an organisation is primarily a creator or user of knowledge and the second addresses whether the primary sources of knowledge are internal or external. These together will provide the strategic framework in which knowledge management strategy needs to be developed. Combining the knowledge exploitation vs exploration orientation of the organisation with its internally vs externally acquired orientation towards knowledge strategy gives a framework for the KM based virtual organisation as shown in Figure 3. 


\begin{tabular}{|l|l|l|l|l}
\hline Unbounded & & & Aggressive & $\begin{array}{l}\text { KM/based } \\
\text { Virtual } \\
\text { Network }\end{array}$ \\
\hline External & & & & $\begin{array}{l}\text { Traditional } \\
\text { Organisation }\end{array}$ \\
\hline Internal & Conservative & & & \\
& $\begin{array}{llll}\text { Exploiter/ } \\
\text { Anticipated }\end{array}$ & $\begin{array}{l}\text { Explorer/ Emergent } \\
\text { Innovator/ } \\
\end{array}$ & Opportunist
\end{tabular}

Figure 3. Framework for knowledge Strategy (adapted from Zack, 1999)

An awareness of these types of change allows the Ministry to experiment and learn as it uses the technology over time. Most importantly, it offers a systematic approach with which to understand and better manage the realities of technologybased change in organisations today.

\subsection{The Arena - Agency Wide Intranet}

The Arena provides staff with ready access to both Departmental and Public Sector wide policy and procedures together with access to detailed resource management tools. This ensures equity within the Ministry as well as promoting excellence in service delivery and the capacity to truly deliver accountability. The Arena allows access to Ministry operational plans and achievement documentation including the identification of issues and projected activity. This information is fundamental to corporate management processes and decision making at a branch, divisional and executive level.

Access to financial reports was previously provided only to Managers and only in hard copy format once a month. There was no facility for forecasting commitments and being mindful of what discretionary funds were truly available. The Arena provides the opportunity to change all that, in particular, all financial reports are now available on line to all staff; the reports can be updated on a daily basis providing much more reliable and accurate information; the capacity can be available to capture forecasting information.

In addition to financial resource information, staff have the ability to access their current leave and payroll information. This information is also fundamental as a mechanism to assist managers to manage leave liabilities within their area and, through the reporting and charting function to manage staff availability. Even a simple tool such as the on line telephone information function has had a major impact within the Ministry. In addition to providing the telephone numbers and photographs of all staff, it also includes information on staff functions and responsibilities and tracking whether a staff member is in the office.

The Arena proactively provides Ministry staff with access to other corporate information. Staff are kept informed of coming events, new initiatives and important projects through a daily newsflash, Ministry notice board and calendar of 
events. A summary of the three areas is displayed on all screens each morning when staff first begin their daily work.

In terms of document management, The Arena provides ready access to a Ministerial tracking system that enables all staff to view information on current Ministerial correspondence, who is the responsible officer and when it is due for completion. This system assists in ensuring that all Ministerial correspondence is tracked and actioned in a timely manner. The internal document management system (IDMS) has greatly assisted staff in providing the best possible service to their clients. The system has provided staff with the ability to search for information stored in any document within the Ministry, value add to this information and provide far more extensive and better researched information to their clients. Staff are able to search through up to 40,000 documents and locate the required document in less than 4 seconds. As the Director of Business Management stated:

Implementation of the Arena has, for the first time provided the opportunity to make 'Accountability' easy. Policies and Procedures, Financial and Human Resource information are at the fingertips of all staff - there is no question about expectations and obligations; about what resources are available, what have been used, what is committed and what is still available. What was planned to be done, what has been done and what is proposed to be done is continually visible.

The Arena has provided the Ministry with a comprehensive set of Knowledge Management Tools that when coupled with staff skills and expertise produces true knowledge as defined by Moody and Shanks and enables the Ministry to provide value to its clients. The Arena is more than an Intranet. The Arena combines the power of Internet and communications technology to bring together a geographically disperse organisation to enable a consolidated approach to the provision of service to clients through access to current information and the ability to form collaborative links across the organisation. It is an integrated approach to identifying, managing and sharing all of the enterprise's information assets. 


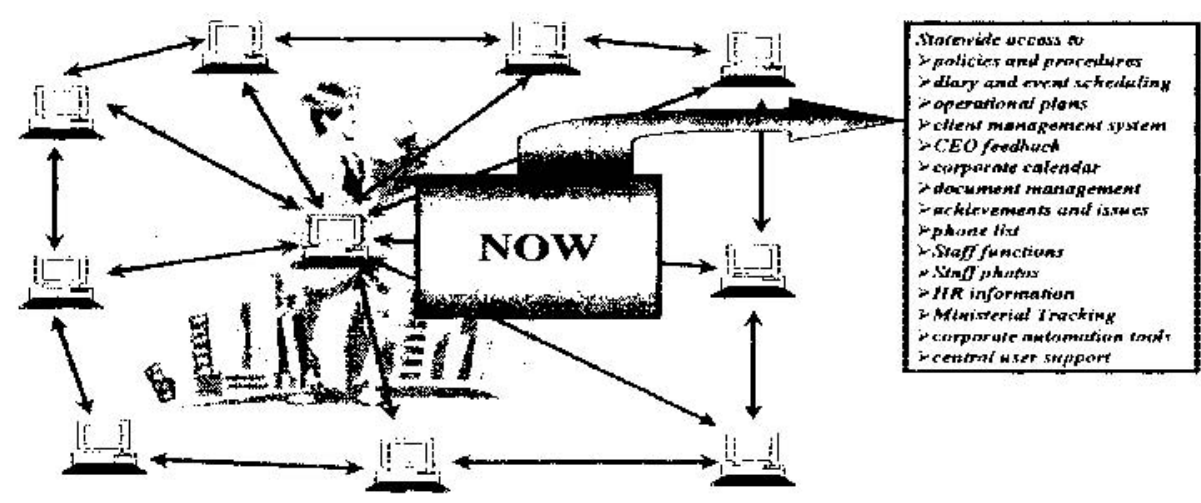

Figure 2. Ministry Information Infrastructure Post Arena

\section{LESSONS LEARNED}

Newell et al (1999) states that resources, networks and knowledge are very important during the implementation stage of an Intranet. Prior to embarking on the project the Ministry of Sport and Recreation recruited senior managers who had had experience implementing similar systems in other Government agencies. The Information Management and Communications Branches were reviewed and additional staff recruited in readiness for the project. At the outset of the project a wide variety of Government agencies were consulted to determine what similar initiatives had been undertaken to leverage their knowledge base. This recruitment and environmental scan created the foundation for the implementation whilst paying attention to resources, establishment of external networks and strategic knowledge.

Newell also discusses the importance of organisational control over the design and use of technology when implementing a project aimed at increasing organisational-wide knowledge management processes (Newell, Scarborough, Hislop and Swan 1999). From the outset of this project it was determined that a centralised approach needed to be taken to ensure that it succeeded. Prior to the project a few different groups had worked on developing an intranet presence for their information. Due to lack of coordination, resources and knowledge of implementing such a project none had succeeded in being placed into production within the organisation. Independent Intranets could be said to be increasing the barriers, with electronic silos reinforcing the already existing functional barriers (Newell, Scarborough, Hislop and Swan 1999).

The setting up of an IT Steering Committee representative of all sections of the organisation, the numerous informational sessions, and knowledge gathering all 
ensured a positive outcome for the project. Attention was given to both internal and external networks, the resources required to tackle the project which led to the development of an appropriate knowledge base.

Knowledge management issues include developing, implementing and maintaining the appropriate technical and organizational infrastructures to enable knowledge sharing (Butler 2000). The Arena includes databases, documents and policies and procedures. It includes technical infrastructures that allow the exchange of knowledge between organisational members regardless of where their office is located within Western Australia. Within the organisation the Arena stands for an Intranet system and the communication links that enables collaboration, upward, downward and horizontal information flows that assists in generating corporate knowledge and the provision of services to clients.

Dyerson talks of three building blocks, appropriation - retention and effective utilisation of internal knowledge, teamworking - integration of diverse knowledge bases and learning - acquisition and exploitation of external knowledge (Dyerson and Mueller 1999). The Ministry have begun to tackle the first two from an explicit knowledge viewpoint and are now planning to look at the third. This will lay a solid foundation for expanding their KM strategy and moving towards a tacit knowledge strategy as identified in Figure 3.

The next step for the Ministry of Sport \& Recreation is to tackle how to capture and/or utilise the unarticulated expertise and experience within its people. Davenport talks of Knowledge Management, Round Two. He indicates that round one was related to managing knowledge management or capturing information and placing it in one place. He indicates essentially this is the building of an Intranet (Davenport 1999). Round two is capturing the tacit knowledge. Capturing this knowledge must be 'baked' into the job. Certainly the Ministry of Sport \& Recreation have not contemplated the how, why or who for stage two and have a long way to go prior to embarking on an implementation strategy. Standing and Benson talk of organisational culture and how cultural change is a critical factor (Standing and Benson 2000). Within the Ministry of Sport \& Recreation there are signs of change fatigue. Since January 2000 the organisation has implemented a completely new technology infrastructure, asked staff to change the way they had worked in the past as well as putting in place policies and procedures that make staff far more accountable than ever before as well as putting in place reporting mechanisms for all projects being undertaken. This rapid change has dramatically changed the culture within the organisation, and staff are now requesting a slow down of the pace of change. It could be said that the current climate and organisational culture are not conducive to implementing this side of Knowledge Management.

Email is utilised throughout the organisation to quickly disseminate knowledge. A message system for staff to communicate directly with the CEO has been established. The messages sent utilising this system can only be read by the CEO. 
Therefore there is no filtering mechanism or restrictions on the comments being made. This has engendered a free flow of information and developed a culture of open and frank discussion whilst encouraging constructive criticism and advice across divisional and project boundaries. This is different to other research findings where they found that communications from the lower level staff to senior management was filtered, restricted and moved through slower channels (Standing and Benson 2000).

Moody identifies four broad objectives

1. Create knowledge repositories;

2. Improve knowledge access;

3. Enhance the knowledge environment; and

4. Manage knowledge as an asset. (Moody and Shanks 1999)

The Ministry has tackled their Knowledge Management project in such a way as to take into account and meet the first three objectives. They have ensured the involvement of all staff at the early stages to obtain 'buy-in' and by doing an environmental scan up front been able to implement systems rapidly whilst not falling into pitfalls that other organisations had encountered. The project also confirms Nissen's, Kamel's and Segupta's statement that groupware offers infrastructural support for knowledge work and enhances the environment in which knowledge artefacts are created and managed, yet the management of knowledge remains indirect (Nissen, Kamel and Sengupta 2000). As previously stated the Ministry have yet to progress into the area of capturing tacit knowledge, yet they have developed an infrastructure that clearly supports knowledge work particularly in a geographically disperse or virtual environment. The environment also facilitates the reuse of knowledge across the organisation.

\section{CONCLUSION}

This paper examines the initial stages of a Knowledge Management initiative within a Western Australian Government Organisation. It is currently too early to tell what impact this model has had on the goals the Ministry have set out to achieve nor the effect it has had turning knowledge into organisational action. As Pfeffer states 'most firms' efforts consist of investing in knowledge repositories such as intranets and implementing technologies to facilitate collaboration What most firms haven't done very much is build knowledge into products and services' (Pfeffer and Sutton 1999). Whilst this is certainly the case at the Ministry of Sport \& Recreation further research is required over a period of time to determine if they do progress beyond this.

In conclusion, lessons can be learned from the pragmatic approach taken by the Ministry of Sport \& Recreation. That is to start with the basics and to deliver organisational wide information and communications infrastructure that allows for 
open communication through all levels of the organisation and access to information regardless of physical location. If organisations embarking on KM programmes take a realistic perspective then they are more likely to value the benefits that accrue from the changes and techniques rather than expecting a radical transformation to widespread sharing of knowledge (Standing and Benson 2000).

\section{REFERENCES}

Butler, Y. (2000). "Knowledge Management - if only you knew what you knew.” The Australian Library Journal (February 2000): 33-43.

Davenport, T. (1999). "Knowledge Management, Round Two." CIO Magazine(November 1, 1999).

Dawson, R. (2000). Developing Knowledge -Based Client Relationships. Melbourne, ButterWorth-Heineman.

Dyerson, R. and F. U. Mueller (1999). "Learning, teamwork and Appropriability: Managing Technological Change in the Department of Social Security." Journal of Management Studies 36(5): 629 - 652.

Kanter, J. (1999). “Knowledge Management, Practically Speaking.” Information Systems Management(Fall): 7-15.

Moody, D. L. and G. G. Shanks (1999). "Using Knowledge Management and The Internet to Support Evidence Based Practice: A Medical Case Study." Proceedings of the 10th Australasian Conference on Information Systems: 660-676.

Newell, S., H. Scarborough, D. Hislop and J. Swan (1999). "Intranets and Knowledge Management: Complex Processes and Ironic Outcomes." Proceedings of the 32nd Hawaii International Conference on System Sciences.

Nissen, M., M. Kamel and K. Sengupta (2000). "Integrated Analysis and Design of Knowledge Systems and Processes.” Information Resources Management Journal 13(1): 24-43.

Pfeffer, J. and R. I. Sutton (1999). "Knowing "what" to do is not enough: Turning knowledge into action." California Management review (Fall).

Standing, C. and S. Benson (2000). "Organisational Culture and Knowledge Management." PACIS conference, Hong Kong..

Sveiby, K. E. (1997). The New Organisational Wealth: Managing and Measuring Knowledge-

Based Assets. San Fransisco, Berret-Loehler Publishers.

Vail, E. F. (1999). "Knowledge Mapping: Getting Started With Knowledge Management." Information Systems Management(Fall): 16-23.

Zack, M. H. (1999) Developing a knowledge strategy. California Management Review; Berkeley; Spring. 